\title{
INFLUENCE OF TECHNICAL CHARACTERISTICS ON THE ROLLING SHEAR PROPERTIES OF CROSS LAMINATED TIMBER BY MODIFIED PLANAR SHEAR TESTS
}

\author{
Zhiqiang Wang ${ }^{1}$, Jianhui Zhou ${ }^{2, \star}$, Weiqun Dong ${ }^{1}$, Yue Yao ${ }^{1}$, Meng Gong ${ }^{2}$
}

In memoriam of Dr. Thomas C. MANNES

\begin{abstract}
Rolling shear properties of cross laminated timber are important mechanical properties for its structural application. To evaluate the influence of technical characteristics such as edge-gluing and gap size in the cross layers, on the measurement of rolling shear modulus and strength of cross laminated timber, three-layer spruce-pine-fire cross laminated timber shear block specimens with and without edge-gluing, with gaps of $2 \mathrm{~mm}, 4 \mathrm{~mm}$ and $6 \mathrm{~mm}$, were tested by a modified planar shear test method. The mean values of rolling shear strength and modulus of No. 2 visual grade spruce-pine-fire cross laminated timber were 1,32 MPa and $111 \mathrm{MPa}$ with coefficients of variance of $20 \%$ and $28 \%$, respectively, regardless of technical characteristics. The characteristic rolling shear strength of all groups of three-layer cross laminated timber specimens was determined to be $0.88 \mathrm{MPa}$. The results indicated that the rolling shear strength and modulus values used in current design practice of spruce-pine-fire cross laminated timber were conservative. It was found that edge-gluing and gap size had a significant influence on measuring rolling shear strength rather than apparent rolling shear modulus by the modified planar shear test method. With the gap size larger than $2 \mathrm{~mm}$, its influence on measuring rolling shear strength became negligible. The three major initial failure modes identified for the cross layer regardless of technical characteristics were rolling shear failure along the growth ring, tension perpendicular to grain failure in wood pith and tension perpendicular to grain failure along the wood ray.
\end{abstract}

Keywords: Edge-gluing, fir, gap size, mechanical properties, pine, spruce, strength.

\section{INTRODUCTION}

Cross laminated timber (CLT) as an innovative engineered wood product has gained increasing popularity in residential and non-residential construction as roof, floor, and wall components with the development of mass timber buildings throughout the world (Brandner et al. 2016). Thanks to its crosswise laminating structure, CLT achieves better dimensional stability and stiffness homogeneity than the lumber pieces used for CLT production. Due the existence of cross layers with radial-tangential cross sections, the transverse shear strength and stiffness of CLT are relatively low compared to its in-plane bending strength and stiffness, leading to excessive deflection and shear failure along the growth ring, known as rolling shear failure, when subjected to out-of-plane load (Sylvain and Marjan 2011). The so-called rolling phenomenal along growth ring in the radial-tangential cross section of wood is due to different mechanical properties of the late and early wood in one growth ring (Fellmoser and Blass 2004). Rolling shear strength and stiffness are critical to the performance of CLT structural compo- 
nents, especially for CLT floor panels with openings and short span or under point supports (Sylvain and Marjan 2011).

Research on measuring rolling shear properties of CLT has been reported in several studies. Fellmoser and Blass (2004) measured the rolling shear modulus of spruce by beam vibration method, which ranged from 40 to $80 \mathrm{MPa}$. Zhou et al. (2014) recommended the two-plate planar shear test over short-span bending tests for measuring the rolling shear properties of wood used as cross layers in CLT. The average rolling shear strength and modulus of No. 3 visual grade black spruce were measured to be $1,09 \mathrm{MPa}$ and $136 \mathrm{MPa}$, respectively. It was also found that growth ring orientation or sawing pattern had a significant effect on rolling shear modulus, while no effect on rolling shear strength was found (Zhou 2013). Ehrhart et al. (2015) measured the rolling shear strength and moduli of some European timber species including Norway spruce, birch, ash, poplar, beech and pine by planar shear tests for their application in producing CLT. It was found that the width to thickness ratio was linear to both shear modulus and strength. The planar shear tests were conducted with a wood block specimen glued to two pieces of metal plates, the so-called two-plate test specimen. However, the preparation of twoplate test specimen with metal plates is quite tedious because the gluing and cleaning of metal plates require lots of time and efforts. Gong and Chui 2015, Gong et al. 2015 adopted a modified approach using a sandwich specimen cut directly from a CLT panel for measuring the rolling shear modulus and strength of cross layer in CLT. The shape of the specimen, i.e. the angle of the two diagonal corners of the specimen, was considered for applying compressive load application. The test method showed great advantage in specimen preparation and experimental setup compared with other reported methods. Li (2017) reported another modified planar shear test method adopted from AS/NZS 2269.1 (2012), which is a standard test method for plywood. Using the modified method, the lamination thickness on rolling shear strength of New Zealand radiata pine CLT was evaluated and the results were compared with those by short-span bending tests. Comparable rolling shear strength values were obtained from both methods and the lamination thickness had a significant effect on rolling shear strength. Both the short-span bending test and planar shear test methods have been adopted in the European CLT standard, BS EN 16351-2015, for evaluating the rolling shear properties of CLT. Aicher et al. (2016) used both methods for evaluating the rolling shear properties of hybrid CLT build-up with spruce outer layers and inner cross-layer of beech wood. Planar shear test resulted in 10-20\% higher rolling shear strength values than short-span bending tests. Above studies showed that the rolling shear properties of wood are not only affected by its macro and micro characteristics such as growth ring, sawing pattern, thickness and density but also testing methods.

Since non-edge gluing and gaps between lumber pieces in the same layer allow spaces for swelling and shrinking of lumber pieces, edge-gluing and gaps are important technical characteristics according to some manufactures (Brandner 2013). However, it was also found that non-edge gluing and gaps negatively affected the physical and mechanical properties of CLT (Brandner et al. 2017, Niederwestberg et al. 2016, Zhou et al. 2017), which should be taken into consideration regarding with fire design, airborne sound, air tightness, joining technique and appearance quality. It is thought that such manufacturing parameters may have an effect on the measured rolling shear properties based on the planar shear test methods by Gong and Chui (2015) and in BS EN 16351 (2015). Non-edge gluing and gaps can induce stress concentration and initial crack of failure during testing. This study aims to evaluate the effect of edge-gluing and gaps, on the rolling shear properties of CLT and failure mechanisms using a modified planar shear test method.

\section{MATERIALS AND METHODS}

\section{CLT shear block specimen preparation}

The CLT shear block specimens were fabricated using No. 2 visual grade spruce-pine-fir (SPF) lumber pieces imported from Canada. The dimension of the lumber pieces was $38 \mathrm{~mm}$ (thickness) $\times$ $89 \mathrm{~mm}$ (width) $\times 2,44 \mathrm{~m}$ (length). The lumber pieces had a mean density of $470 \mathrm{~kg} / \mathrm{m}^{3}$ and an average moisture content of 14,2\%. One-component polyurethane adhesive (Purbond HB S709) was used for face and edge gluing of the three-layer CLT test specimens. The three-layer CLT shear block specimen 
consisted of lumber three pieces in the cross layer, which was supposed to simulate the specimen cut directly from a full-size CLT panel. Five groups of specimens were prepared with cross layers being edge-glued and without, and with gaps of $2 \mathrm{~mm}, 4 \mathrm{~mm}, 6 \mathrm{~mm}$, which were labeled as group A, B, C, $\mathrm{D}, \mathrm{E}$, respectively. The dimensions and configurations of each group are shown in Figure 1. Due to the gaps in group $\mathrm{C}, \mathrm{D}$, and $\mathrm{E}$, the top and bottom layers were slightly longer than those in group A and $\mathrm{B}$. The lumber pieces were pre-cut and then pressed with a pressure of 1,0 $\mathrm{MPa}$, an adhesive spread rate of $180 \mathrm{~g} / \mathrm{m}^{2}$ and a pressing time of three hours under the environment temperature between 20 and 25 ${ }^{\circ} \mathrm{C}$. Wood chips of $2 \mathrm{~mm}, 4 \mathrm{~mm}$ and $6 \mathrm{~mm}$ wide were prepared and inserted between the lumber pieces in the cross layers for group C, D, and E, respectively, to ensure the gap size during pressing. Side pressure was applied with a clamp to restrain layer movement under vertical pressure. Ten replicates were prepared for each group.

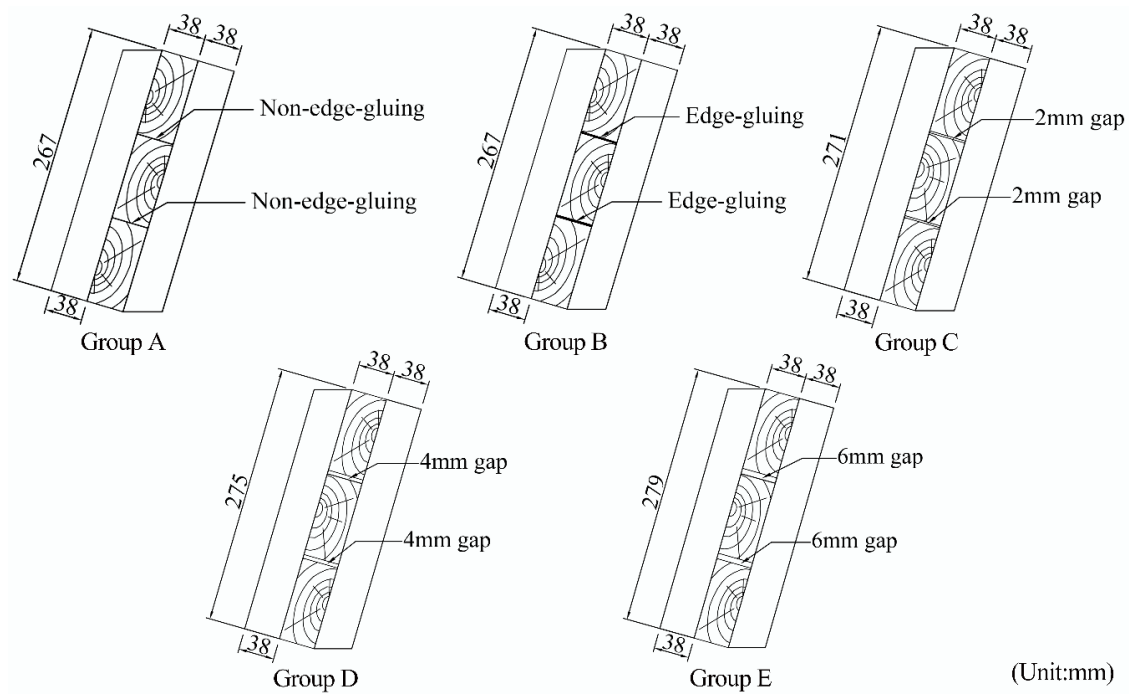

Figure 1. Configurations and dimensions of CLT shear block specimens.

\section{Modified planar shear test}

To date, there is no universal test method for the determination of rolling shear properties of CLT cross-layers. In the well-established North American and European product standard on CLT, ANSI/ APA PRG 320 (ANSI APA 2017) and BS EN 16351 (BS EN 2015), respectively, short-span bending test and planar shear test have been proposed for evaluating the rolling shear modulus and strength of CLT. In this study, the modified planar shear test method reported by Gong and Chui (Gong and Chui 2015) was adopted, which was thought to provide uniform shear stress in the cross layer and guarantee rolling shear failure. The shear test is realized by a compressive load as shown in Figure 2. The key of such modified planar shear test is to ensure the compressive load path pass through the geometric center of the shear block specimen, thus introducing uniform shear stress in the cross layer, especially the lumber piece in the middle. Therefore, an inclination $(\alpha)$ is introduced, which can be calculated by,

$$
\alpha=\tan ^{-1}\left[\frac{L-\sqrt{L^{2}-4 t_{0}\left(t_{0}+t_{c}\right)}}{2 t_{0}}\right] \cdot \frac{180}{\pi}
$$

where the $L$ is the length of the specimen, $t_{0}$ and $t_{c}$ are thicknesses of top or bottom layer and cross layer, respectively. 
Given the dimension information in Figure 1, the angles of inclination were $16,6^{\circ} ; 16,3^{\circ} ; 16,1^{\circ}$ and $15,8^{\circ}$ for group $\mathrm{A}$ and $\mathrm{B}$, group $\mathrm{C}$, group $\mathrm{D}$, and group E, respectively. All the shear block specimens were trimmed as shown in Figure 2 to meet the above requirement of inclinations before tests.
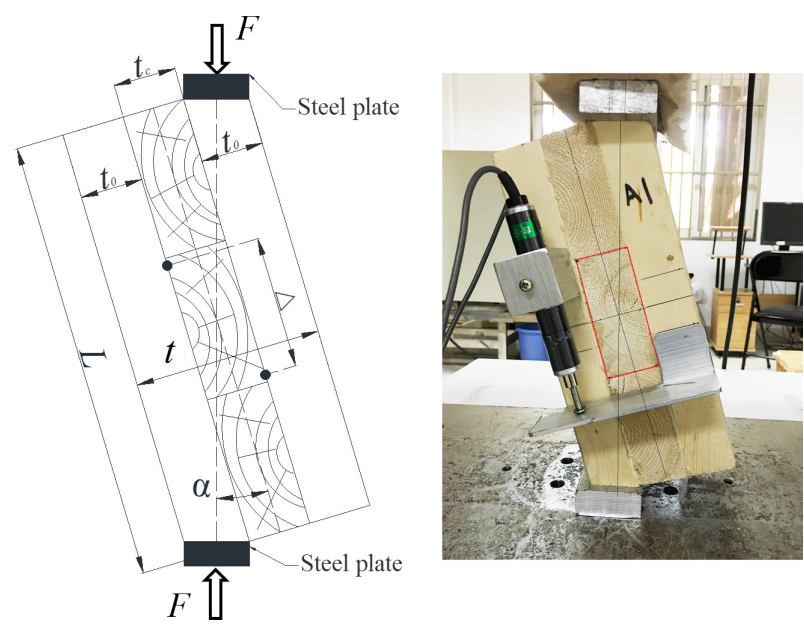

Figure 2. Experimental setup of modified planar shear test.

The modified planar shear tests were performed on a universal testing machine (SHIMADZU, AG-X/AG-IC) with a loading rate of $1,0 \mathrm{~mm} / \mathrm{min}$. Two $25 \mathrm{~mm}$ linear variable differential transducers (LVDTs, TDS-530) were used to measure the displacement on both sides of the specimen. One specimens was randomly selected from each group for a primary test to estimate the peak load level of each group. Then the tests were conducted in two steps. Each specimen was first loaded to $50 \%$ of the estimated peak load, then the load-displacement curve recorded was used to calculate apparent shear modulus $(G)$. After that, each specimen was loaded till failure. The shear strength $(\tau)$ and apparent shear modulus $(G)$ were calculated by,

$$
\begin{array}{r}
\tau=\frac{F_{\max } \times \cos (\alpha)}{L \times w} \\
G=\frac{t_{\mathrm{c}}}{L \times w} \times \frac{F}{\Delta} \times \cos (\alpha)
\end{array}
$$

where, $F_{\max }$ is the peak load, $L$ and $w$ are the length and width of the specimen, $t_{c}$ is the thickness of cross layer, $\frac{F}{\Delta}$ is the slope of the load-deformation curve between 20 and $50 \%$ linear range from the first loading step, $\alpha$ is the angle between shear plane and force direction.

\section{RESULTS AND DISCUSSION}

The summary of rolling shear strength and modulus of all the test groups is presented in Table 1. Overall, the mean rolling shear strength of NO. 2 visual grade SPF was 1,32 MPa with a coefficient of variation $(\mathrm{COV})$ of $20 \%$. Its mean rolling shear modulus was $111 \mathrm{MPa}$ with a COV of $28 \%$ in this 
study. Detailed results and discussion are presented in the following sections.

Table 1. Summary of rolling shear strength and modulus.

\begin{tabular}{|c|c|c|c|c|c|c|}
\hline & Group & A & B & C & D & E \\
\hline \multirow{2}{*}{$\begin{array}{c}\text { Rolling shear } \\
\text { strength }\end{array}$} & Mean & 1,50 & 1,52 & 1,29 & 1,19 & 1,15 \\
\cline { 2 - 7 }$(\mathrm{MPa})$ & Minimum & 1,23 & 1,05 & 1,14 & 0,74 & 0,85 \\
\cline { 2 - 7 } & Maximum & 1,86 & 2,15 & 1,47 & 1,47 & 1,36 \\
\cline { 2 - 7 } & COV & $14 \%$ & $25 \%$ & $9 \%$ & $18 \%$ & $14 \%$ \\
\hline \multirow{3}{*}{$\begin{array}{c}\text { Rolling shear } \\
\text { modulus (MPa) }\end{array}$} & Mean & 109 & 126 & 109 & 107 & 104 \\
\cline { 2 - 7 } & Minimum & 79 & 78 & 78 & 63 & 58 \\
\cline { 2 - 7 } & Maximum & 156 & 188 & 151 & 147 & 168 \\
\cline { 2 - 7 } & COV & $14 \%$ & $25 \%$ & $9 \%$ & $18 \%$ & $14 \%$ \\
\hline
\end{tabular}

\section{Rolling shear strength}

The cumulative distribution of all test results of three-layer SPF CLT is shown in Figure 3. The rolling shear strength of SPF CLT tested falls between 1,0 and 1,6 MPa with only three test values lower than 1,0 MPa. The result is $8,3 \%$ lower than the mean value of 1,44 MPa for the same No. 2 grade SPF in (Gong and Chui 2015). Moreover, the characteristic rolling shear strength, i.e. the $5 \%$ quantile value, was $0,88 \mathrm{MPa}$ with a confidence interval between 1,24 and 1,34 MPa at the confidence level of 95\% according to the nonparametric approach in ASTM D2915-10 (ASTM 2010). In current CLT design guides and codes, the characteristic rolling shear strength is 0,5 MPa for SPF CLT in Canada (Sylvain and Marjan 2011), while in Europe, the characteristic rolling shear strength is recommended $1,1 \mathrm{MPa}$ for both edge-glued softwood CLT and non-edge-glued CLT made of laminations with a minimum width-to-depth ratio of 4, otherwise $0,7 \mathrm{MPa}$ should be used (BS EN 16351, 2015). The above results of rolling shear strength of the CLT specimens in this study indicates that the current design values of $0,5 \mathrm{MPa}$ of SPF CLT is conservative regardless of edge-gluing and gaps.

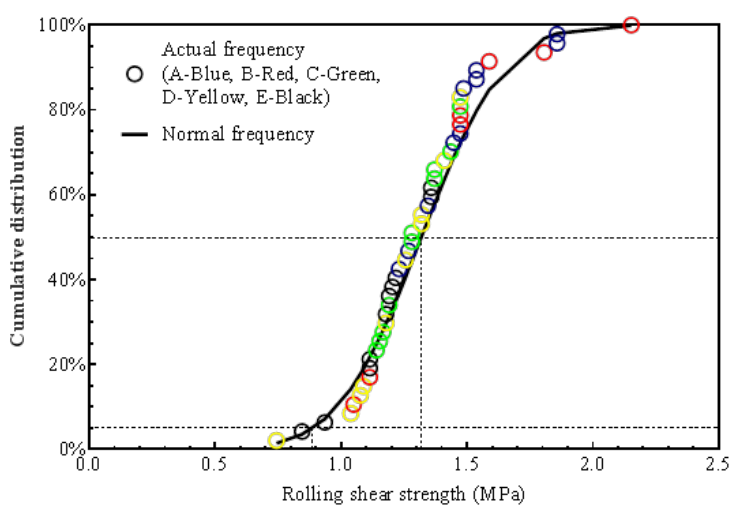

Figure 3. Cumulative frequencies and fitted normal distribution of rolling shear strength of CLT specimens.

With an in-depth investigation of the measured values of each CLT group in Figure 4, differences can be observed among five CLT groups, especially between CLT with gaps and without gaps. The mean values of rolling shear strength decrease if the lumber pieces in the same layer were not edgeglued, and the strength value decreases with the increase of gap size. In the one-way ANOVA test of all five groups, a $p$ value of 0,0012 was obtained and a subsequent Tukey's multiple comparisons test 
was conducted. In Table 2, with a confidence level of $95 \%$ and a cutoff $p$-value of 0,05 there is no significant difference among the mean values of groups $\mathrm{A}, \mathrm{B}$ and $\mathrm{C}$, and among groups $\mathrm{C}, \mathrm{D}$ and $\mathrm{E}$, while a significant difference is observed between $\mathrm{A}$ and $\mathrm{D}, \mathrm{A}$ and $\mathrm{E}, \mathrm{B}$ and $\mathrm{D}, \mathrm{B}$ and $\mathrm{E}$. Therefore, there is no significant difference of rolling shear strength between edge-glued CLT and non-edge-glued CLT without gaps or with gaps less than $2 \mathrm{~mm}$. While the with the increase of gap size from $2 \mathrm{~mm}, 4 \mathrm{~mm}$ to $6 \mathrm{~mm}$, such difference becomes significant compared with edge-glued CLT and non-edge-glued CLT without gaps. The results to some extends proved the recommendation on a reduced characteristic rolling shear strength for non-edge-glued CLT product in BS EN 16351-2015. The reason for a reduced rolling shear strength due to gap size could be attributed to the increased stress concentration level as well as the redistribution of shear stress with the existence of gaps, which may cause the weak zones in the cross layer, namely early wood or pith, become prone to fail (Ehrhart et al. 2015).

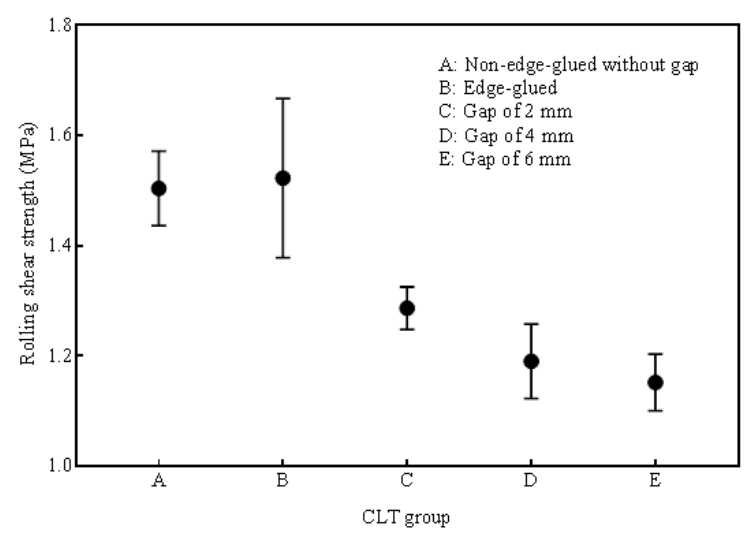

Figure 4. Rolling shear strength for each CLT group.

Table 2. Tukey's multiple comparisons of rolling shear strength of five CLT groups.

\begin{tabular}{|l|l|l|l|}
\hline Paired group & Mean difference & Standard error & Adjusted $p$ Value \\
\hline A vs. B & $-0,0186$ & 0,1095 & 0,9998 \\
\hline A vs. C & 0,2175 & 0,0993 & 0,2035 \\
\hline A vs. D & 0,3138 & 0,0993 & 0,0232 \\
\hline A vs. $\mathrm{E}$ & 0,3523 & 0,0993 & 0,0082 \\
\hline B vs. C & 0,2361 & 0,1095 & 0,2161 \\
\hline B vs. D & 0,3324 & 0,1095 & 0.0317 \\
\hline B vs. $\mathrm{E}$ & 0,3709 & 0,1095 & 0,0127 \\
\hline C vs. D & 0,0963 & 0,0993 & 0,8673 \\
\hline C vs. $\mathrm{E}$ & 0,1348 & 0,0993 & 0,6578 \\
\hline D vs. E & 0,0385 & 0,0993 & 0,9950 \\
\hline A vs. B & $-0,0186$ & 0,1095 & 0,9998 \\
\hline A vs. C & 0,2175 & 0,0993 & 0,2035 \\
\hline
\end{tabular}

\section{Apparent rolling shear modulus}

The rolling shear modulus of softwood CLT is taken $50 \mathrm{MPa}$ or $1 / 10$ of its shear modulus parallel to grain in current design practice in both North America and Europe, while Zhou et al. (2014) and Gong and Chui (2015) reported a higher value than 0,5 MPa can be used. Ehrhart et al. (2015) recommended the minima minimum value of $100 \mathrm{MPa}$ or $(30+1,75 \times$ width/ thickness) MPa for Norway 
spruce CLT. As seen in Figure 5, the mean value of rolling shear modulus of each CLT ground is very close to each other ranging from 100 to 130 . The edge-glued CLT group had a higher mean value of $126 \mathrm{MPa}$ than the rest. However, the one-way ANOVA test of all five groups showed that there was no significant difference among all five CLT groups with a $p$ value of 0,5992 obtained. Therefore, the edge-gluing and gap size had no significant influence on the measurement of apparent rolling shear modulus of cross layer of CLT by the modified planar shear test, which might be explained by the low stress level during the elastic range of the relative deformation of the specimen under the modified test setup. It was also reported that the rolling shear strength and modulus of cross layer in CLT measured by the modified planar shear test were not affected by the length of the shear block specimen when length was greater than 8 inches (203 mm) (Gong and Chui 2015).

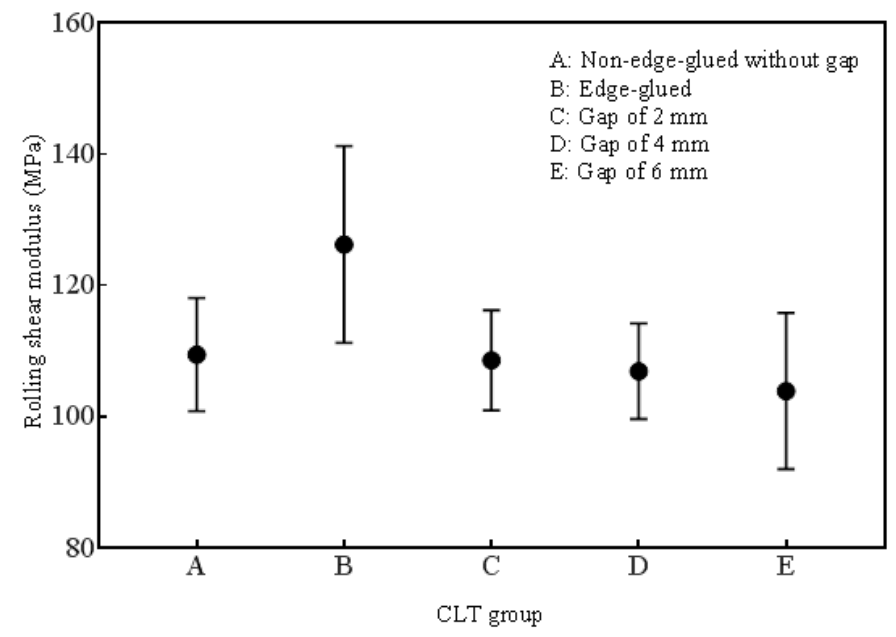

Figure 5. Mean value with standard error of rolling shear modulus for each CLT group.

\section{Rolling shear failure modes}

Typical failure modes of five CLT specimen groups tested were shown in Figure 6. They were all observed to be ductile failure mode regardless of edge-gluing and gap size. Generally, no obvious differences in failure mode were found among the five CLT groups. Three typical failure mechanisms were observed during the modified planar shear tests. The first and most common failure mode was the so-called rolling shear failure shown in Figure 5(c). The cracks were initiated suddenly and propagated along the growth ring. With the shear stress induced perpendicular to the longitudinal direction of CLT, a friction surface is created along the transition from early wood to latewood within a growth ring. Due to the different resistance to shear stresses of early wood and latewood, the increasing shear stress caused the rolling of wood fiber in a single growth ring and finally spread to adjacent layers. The crack(s) stopped at the bonding surface between the outer layers and cross layer causing the final fracture of the test specimen. The second type of initial failure mode usually happened for CLT specimens with cross layers having pith as shown in Figure 5 (a), Figure 5 (b) and Figure 5 (e). With the load approaching peak load, a crack or cracks would suddenly initiate around the pith and then propagated along the growth ring or wood ray direction, which was the primary failure mode for such CLT specimens. It is known that wood pith mainly consists of parenchyma cells and has relatively low mechanical properties. The third failure mode was the shear failure found wood ray as shown in Figure 5 (d). Wood rays always consist of one or two rows of parenchyma cells, which can be a weak zone that cracks are caused by the tension stress perpendicular to grain and propagated along the wood ray direction. During the actual tests, the initial failure may be caused by one of the above described mechanisms, however, with the increase of either load or displacement, the combination of three different failure modes can be observed in the cross layers of a specimen due to very complicated stress redistributions. The findings here agree with the failure mechanisms reported by Nie (2015), who recorded the detailed failure process of CLT cross layers with high speed camera and categorized the initial failure 
modes into three types, tension perpendicular to grain type, rolling shear type and marginal type.

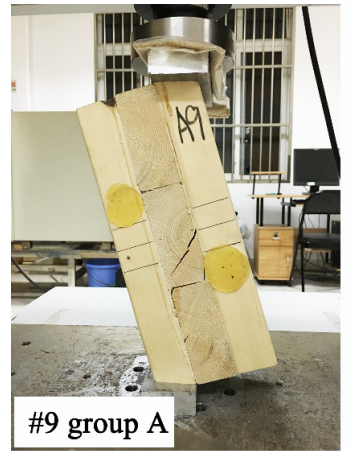

(a)

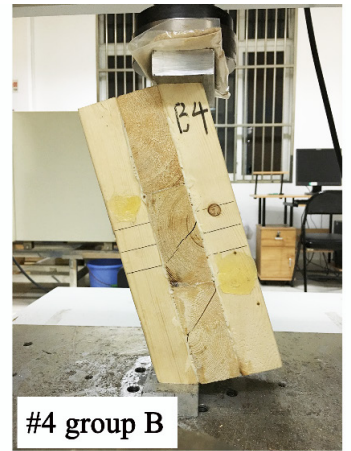

(b)

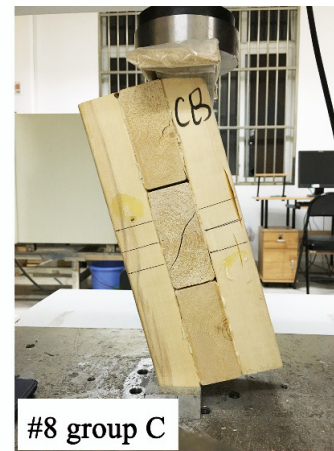

(c)

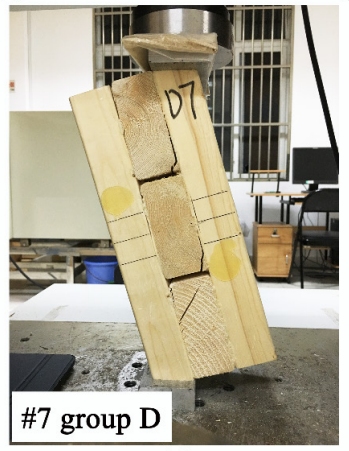

(d)

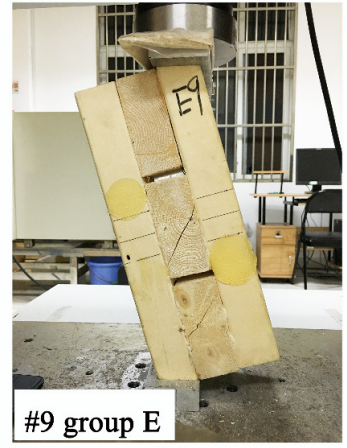

(e)

Figure 6. Typical rolling shear failure during testing.

\section{CONCLUSIONS}

The influence of edge-gluing and gap size was found to be significant on the measuring of rolling shear strength of cross layers in CLT by the modified planar shear test. However, no influence was found for CLT specimens with gap size more than $2 \mathrm{~mm}$ in measuring rolling shear strength and for all CLT specimens in measuring apparent rolling shear modulus.

The characteristic rolling shear strength of all three-layer No. 2 visual grade SPF CLT specimens was $0,88 \mathrm{MPa}$ and the mean rolling shear strength was measured to be $111 \mathrm{MPa}$ with a coefficient of variance of $28 \%$. The results indicated conservative rolling shear strength and modulus values using in current design practice of SPF CLT, which are 0,5 MPa and $50 \mathrm{MPa}$ for SPF CLT. The shear failure mechanism of cross layers in CLT is more complicated than just rolling shear failure. The initial failure modes are found to mainly include rolling shear failure along the growth ring, tension failure perpendicular to grain in wood pith and tension failure perpendicular to grain along the wood ray. Further research may focus on the standard requirements of edge-gluing and gap size with the considerations of width to thickness ratio of cross layer for CLT production.

\section{ACKNOWLEDGMENTS}

This study was funded by National Natural Science Foundation of China (Grant No. 31570559) and the Priority Academic Program Development of Jiangsu Higher Education Institutions (PAPD). 


\section{REFERENCES}

Aicher, S.; Hirsch, M.; Christian, Z. 2016. Hybrid cross-laminated timber plates with beech wood cross-layers. Construction and Building Materials 124: 1007-1018.

ASTM International. 2010. Practice for Sampling and Data-Analysis for Structural Wood and Wood-Based Products. ASTM D2915-10. ASTM International: West Conshohocken, PA

Australian New Zealand Standards. AS/NZS. 2012. Plywood - Structural Part 1: Determination of structural properties - Test methods. AS/NZS 2269.1.2012.

ANSI-APA 2017. Standard for performance-rated cross-laminated timber. ANSI/APA PRG 320. 2017

Brandner, R. 2013. Production and Technology of Cross Laminated Timber (CLT): A State-ofthe-art Report. In Focus Solid Timber Solutions - European Conference on CLT (pp. 3-36). Graz.

Brandner, R.; Dietsch, P.; Dröscher, J.; Schulte-Wrede, M.; Kreuzinger, H.; Sieder, M. 2017. Cross laminated timber (CLT) diaphragms under shear: Test configuration, properties and design. Construction and Building Materials 147: 312-327.

Brandner, R.; Flatscher, G.; Ringhofer, A.; Schickhofer, G.; Thiel, A. 2016. Cross laminated timber (CLT): overview and development. European Journal of Wood and Wood Products 74(3): $331-351$.

BS EN. 2015. Timber structures - Cross laminated timber - Requirements. BS EN 16351. 2015.

Ehrhart, T.; Brandner, R.; Schickhofer, G.; Frangi, A. 2015. European Timber Species with Focus on Cross Laminated Timber (CLT): Test Configuration and Parameter Study. In R. Görlacher (Ed.), Proceedings of 2nd International Network on Timber Engineering Research (pp. 61-75). Sibenik: Timber Scientific Publishing.

Fellmoser, P.; Blass, H. J. 2004. Influence of rolling shear modulus on strength and stiffness of structural bonded timber elements. In CIB-W18 Meeting.

Gong, M.; Chui, Y. H. 2015. Evaluation of Planar Shear Properties of Cross Layer in Massive Timber Panel. Report, University of New Brunswick, Fredericton, Canada.

Gong, M.; Tu, D.; Li, L.; Chui, Y. H. 2015. Planar Shear Properties of Hardwood Cross Layer in Hybrid Cross Laminated Timber. In ISCHP 2015: 5th International Scientific Conference on Hardwood Processing (pp. 85-90). Retrieved from <www.ischp2015.org>

Li, M. 2017. Evaluating rolling shear strength properties of cross-laminated timber by short-span bending tests and modified planar shear tests. Journal of Wood Science 63(4):331-337.

Nie, X. 2015. Failure mechanism of rolling shear failure in cross-laminated timber. Master Thesis, University of British Columbia, Vancuver, Canada.

Niederwestberg, J.; Chui, Y. H.; Gong, M. 2016. Influence of layer and laminate characteristics on shear properties of cross laminated timber and hybrids. In: E. Josef, W. Wolfgang, F. Alireza, \& P. Martina (Eds.), World Conference on Timber Engineering. Vienna: TU-MV Media Verlag GmbH. pp. $1081-1090$

Sylvain, G.; Marjan, P. 2011. Structure design of cross-laminated timber elements. In G. Sylvain \& P. Ciprian (Eds.), CLT Handbook (1st ed., pp. 114-185). FPInnovations.

Zhou, J.; Chui, Y. H.; Gong, M.; Hu, L. 2017. Elastic properties of full-size mass timber panels: Characterization using modal testing and comparison with model predictions. Composites 
Part B: Engineering 112: 203-212.

Zhou, Q. 2013. Develoment of evaluation methodology for rolling shear properties in cross laminated timber (CLT). Master Thesis, University of New Brunswick, Fredericton, Canada.

Zhou, Q.; Gong, M.; Chui, Y. H.; Mohammad, M. 2014. Measurement of rolling shear modulus and strength of cross laminated timber fabricated with black spruce. Construction and Building Materials 64: 379-386. 